Article

\title{
Preparation of Polyethylene Glycol-Ginsenoside Rh1 and Rh2 Conjugates and Their Efficacy against Lung Cancer and Inflammation
}

\author{
Ramya Mathiyalagan ${ }^{1,+}$, Chao Wang ${ }^{2,3,+}$, Yeon Ju Kim ${ }^{2}$, Verónica Castro-Aceituno ${ }^{2}{ }^{(\mathbb{C}}$, \\ Sungeun Ahn ${ }^{2}$, Sathiyamoorthy Subramaniyam ${ }^{2,4}$, Shakina Yesmin Simu ${ }^{1}$, \\ Zuly Elizabeth Jiménez-Pérez ${ }^{1}$, Deok Chun Yang ${ }^{1,2, *}$ and Seok-Kyu Jung ${ }^{2, *}$ \\ 1 Graduate School of Biotechnology, College of Life Science, Kyung Hee University, Yongin-si, \\ Gyeonggi-do 17104, Korea; ramyabinfo@gmail.com (R.M.); simu.sha2@gmail.com (S.Y.S.); \\ zejp78@gmail.com (Z.E.J.-P.) \\ 2 Department of Oriental Medicinal Biotechnology, College of Life Science, Kyung Hee University, Yongin-si, \\ Gyeonggi-do 17104, Korea; chaow@sdut.edu.cn (C.W.); yeonjukim@khu.ac.kr (Y.J.K.); \\ ca.veronica@khu.ac.kr (V.C.-A.); se8688@gmail.com (S.A.); s.sathiyamurthi@gmail.com (S.S.) \\ 3 Institute of Biomedical Research, School of Life Sciences, Shandong University of Technology, Zibo 255000, \\ Shandong, China \\ 4 Department of Biotechnology, Dr.N.G.P., Arts and Science College, Coimbatore 641048, Tamil Nadu, India \\ * Correspondence: dcyang@khu.ac.kr (D.C.Y.); seokkyujung@gmail.com (S.-K.J.) \\ + These authors contributed equally to this work.
}

Academic Editor: René Csuk

Received: 7 October 2019; Accepted: 26 November 2019; Published: 29 November 2019

\begin{abstract}
Low solubility and tumor-targeted delivery of ginsenosides to avoid off-target cytotoxicity are challenges for clinical trials. In the present study, we report on a methodology for the synthesis of polyethylene glycol (PEG)-ginsenoside conjugates through a hydrolysable ester bond using the hydrophilic polymer polyethylene glycol with the hydrophobic ginsenosides Rh1 and Rh2 to enhance water solubility and passive targeted delivery. The resulting conjugates were characterized by ${ }^{1} \mathrm{H}$ nuclear magnetic resonance $\left({ }^{1} \mathrm{H}\right.$ NMR) and Fourier-transform infrared spectroscopy (FT-IR). ${ }^{1} \mathrm{H}$ NMR revealed that the C- 6 and C-3 sugar hydroxyl groups of Rh1 and Rh2 were esterified. The conjugates showed spherical shapes that were monitored by field-emission transmission electron microscopy (FE-TEM), and the average sizes of the particles were $62 \pm 5.72 \mathrm{~nm}$ and $134 \pm 8.75 \mathrm{~nm}$ for PEG-Rh1and PEG-Rh2, respectively (measured using a particle size analyzer). Owing to the hydrophilic enhancing properties of PEG, PEG-Rh1 and PEG-Rh2 solubility was greatly enhanced compared to Rh1 and Rh2 alone. The release rates of Rh1 and Rh2 were increased in lower $\mathrm{pH}$ conditions ( $\mathrm{pH}$ 5.0), that for pathophysiological sites as well as for intracellular endosomes and lysosomes, compared to normal-cell $\mathrm{pH}$ conditions ( $\mathrm{pH}$ 7.4). In vitro cytotoxicity assays showed that the PEG-Rh1conjugates had greater anticancer activity in a human non-small cell lung cancer cell line (A549) compared to Rh1 alone, whereas PEG-Rh2 showed lower cytotoxicity in lung cancer cells. On the other hand, both PEG-Rh1 and PEG-Rh2 showed non-cytotoxicity in a nondiseased murine macrophage cell line (RAW 264.7) compared to free Rh1 and Rh2, but PEG-Rh2 exhibited increased efficacy against inflammation by greatly inhibiting nitric oxide production. Thus, the overall conclusion of our study is that PEG conjugation promotes the properties of Rh1 for anticancer and $\mathrm{Rh} 2$ for inflammation treatments. Depends on the disease models, they could be potential drug candidates for further studies.
\end{abstract}

Keywords: Korean ginseng; ginsenoside Rh1; ginsenoside Rh2; polyethylene glycol; conjugation; nanoparticles; lung cancer; inflammation 


\section{Introduction}

According to a World Health Organization report (https://www.who.int/news-room/fact-sheets/ detail/cancer), lung cancer (1.76 million deaths) is the leading cause of cancer mortality in humans [1], beating out colorectal (862,000 deaths), stomach (783,000 deaths), liver (782,000 deaths), and breast (627,000 deaths) cancer. Chemotherapy is an important part of cancer treatment, and numerous anticancer drugs have been reported [2]. However, pitfalls exist in the physiochemical properties of cancer drugs, including poor aqueous solubility, a short half-life in the body, low bioavailability, and target-specific cytotoxicity in the cancer microenvironment $[3,4]$. These factors lead to poor antitumor effects, systemic toxicity, and other side effects in patients and reduce the quality of life and clinical applications. To surmount these issues, numerous water-soluble polymers with good biocompatible and biodegradable properties have been applied as carriers for the delivery of these anticancer drugs, and they have exhibited various advantages [5-9]. Among these, polyethylene glycol (PEG) is a water-soluble, nontoxic polymer that has been approved by the Food and Drug Administration (FDA) as "Generally Regarded as Safe (GRAS)", and it is used in targeted delivery [10-12]. There are some PEGylated drugs that have been approved by the FDA, as well as four small-molecule drugs in clinical trials [13]. PEG has been reported to improve the solubility of drugs [14], increase the circulation time of drugs in the bloodstream by preventing them from reticuloendothelial clearance, enhance accumulation in tumor tissues through an enhanced permeation and retention (EPR) effect, induce a stimuli-responsive release of the conjugated drugs into the tumor microenvironment by reducing the cytotoxicity in the normal tissues, improve the half-life of drugs in the body compared to free drugs, and prevent the degradation of drugs by intestinal enzymes [13,15-23].

Ginsenosides are versatile phytochemical drug candidates from the oriental medicinal herb Panax ginseng that have been reported on for their various pharmacological efficacies [24]. Various technologies have been applied to elucidate the biosynthesis mechanism of ginsenosides in ginseng and its bioconversion of major to minor ginsenosides (which possess more numerous bioactivities than the major ginsenosides) [25-27]. Structurally, ginsenosides are classified into protopanaxadiols (PPDs), protopanaxatriols (PPTs), and oleanane-type saponins according to the glycosidic linkage of sugar chains to their triterpenoid aglycone [28]. Further, ginsenosides are grouped as major and minor based on the number of sugar molecules attached [28]. Although various efficacies of ginseng crude extract and ginsenosides have been reported, the majority of major ginsenosides are hydrolyzed into minor ginsenosides after oral administration [29]. Besides improved pharmacological efficacies and the better systemic circulation of minor ginsenosides (PPD type CK (Compound K), Rh2, and PPD aglycone and PPT type Rh1, F1, and PPT aglycone), their hydrophobicity, targeted delivery into pathophysiological sites such as tumors, and propensity to cause inflammation by avoiding normal cell cytotoxicity, are crucial factors in applying ginsenosides in clinical trials [24]. Moreover, conjugates, especially those with nanoparticles, have gained more attention than the original form of ginsenosides due to their enhanced pharmacological effects [17,30-34]. In recent years, studies on ginsenoside Rh1 (PPT type) [35-42] and Rh2 (PPD type) [43-49] have focused on their anti-inflammatory, anticancer, and immune conditioning abilities. Rh2 and Rh1 both have a similar structure, but vary in terms of one glucose molecule at C-3 (PPD type) and C-6 (PPT type): they also have higher cell uptake ratios compared to major ginsenosides. Moreover, new standardization practices are preferred for ginseng products with minor ginsenosides, such as Rh2. Accordingly, in the present study, PEG conjugation was applied to ginsenosides $\mathrm{Rh} 1$ and $\mathrm{Rh} 2$ to increase their solubility, their cytotoxicity in tumor cells, and their anti-inflammatory properties, with lower cytotoxicity in normal cells. The resultant PEG-Rh1and PEG-Rh2 conjugates were characterized using standard techniques $\left({ }^{1} \mathrm{H}\right.$ NMR, FT-IR, and field-emission transmission electron microscopy (FE-TEM)) and particle size analysis. Solubility and the in vitro release of $\mathrm{Rh} 1$ and $\mathrm{Rh} 2$ were studied under pathophysiological ( $\mathrm{pH}$ 5.0) and physiological ( $\mathrm{pH} 7.4$ ) conditions. In addition, in vitro cytotoxicity was assessed in a human lung cancer cell line (A549) and in murine macrophage cell line (RAW 264.7). Finally, the anti-inflammatory properties of PEG-Rh1 
and PEG-Rh2 were evaluated through the inhibition of nitric oxide (NO) production in the RAW 264.7 cell line.

\section{Results and Discussion}

We aimed to increase the solubility, antitumor activity, and anti-inflammation activity of Rh1 and Rh2 and to decrease cytotoxicity to normal cells. Self-assembled PEG micelles were prepared with an acid-liable ester bond. The conjugates were expected to accumulate more in the tumor tissues through an EPR effect as well as through inflammation and to release Rh1 and Rh2 in the intracellular lysosome and endosome due to acidic $\mathrm{pH}$ conditions. Further, $\mathrm{Rh} 1$ and $\mathrm{Rh} 2$ were expected to target the nucleus to degrade cancer cell genetic materials, as is illustrated in the graphical abstract.

\subsection{Synthesis and Physiochemical Characterization of PEG-Rh1 and PEG-Rh2 Conjugates}

Initially, the chemical synthesis of the PEG-ginsenoside conjugates was completed in two steps, as shown in Figure 1. In the first step, the hydroxyl group in PEG was modified to a carboxyl group (PEG-COOH), which was confirmed by ${ }^{1} \mathrm{H}$ NMR to have the characteristics of a succinic acid peak at $2.6 \mathrm{ppm}$. Next, the ester bonds between PEG-COOH and Rh1 and Rh2 were synthesized and the ester bond peaks were confirmed by ${ }^{1} \mathrm{H}$ NMR (Figure 2A), as explained in Reference [18]. Though Rh1 and Rh2 ginsenosides possess similar structures and they differ only in terms of the glucose linkage at C-3 and C-6, the conjugation efficacy (228.5 $\mu \mathrm{g}$ of Rh1/1 mg PEG-Rh1 and $192 \mu \mathrm{g}$ of Rh2/1 mg PEG-Rh2) greatly varied (more so than with other reported conjugates) [18].
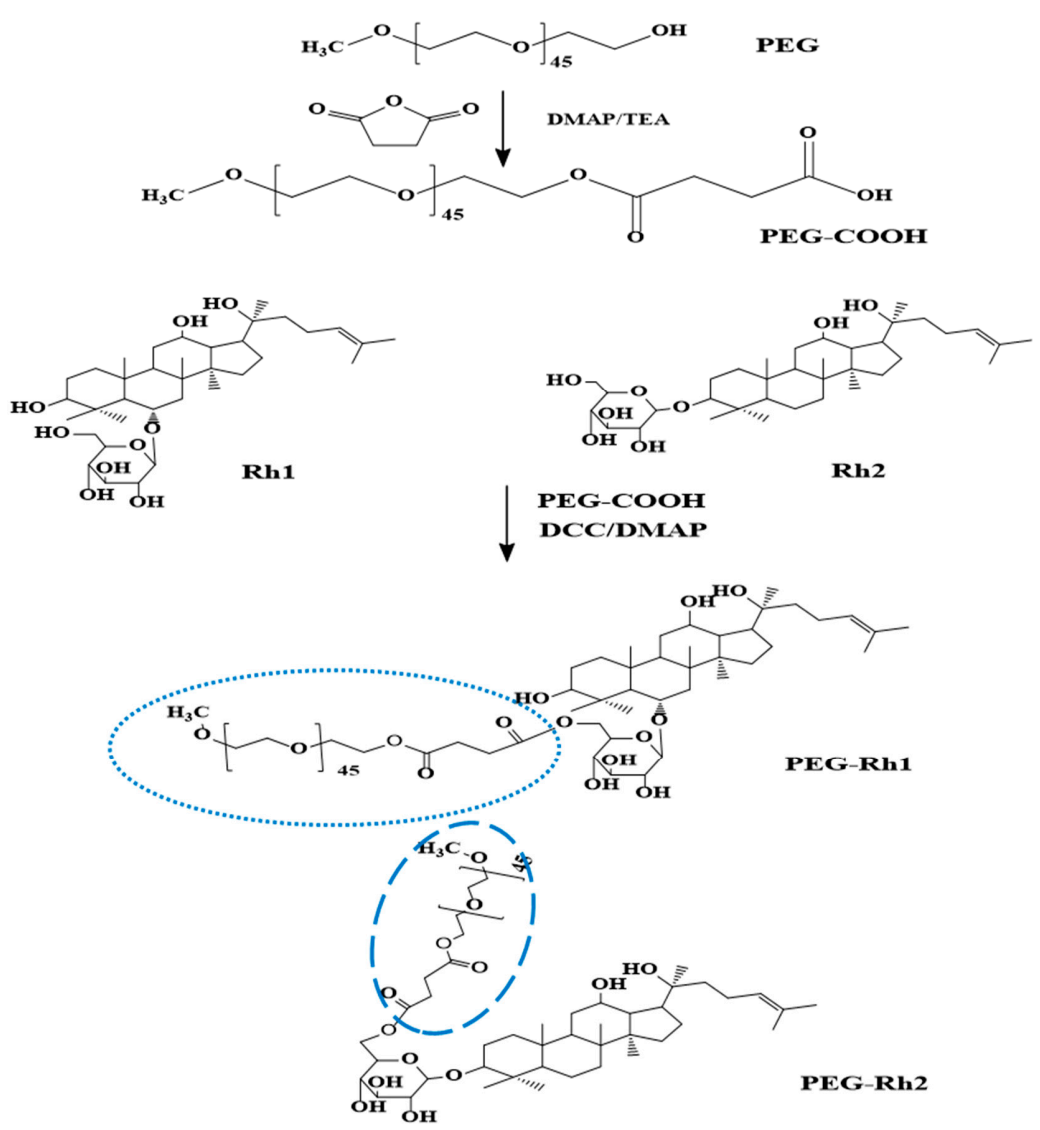

Figure 1. Schematic illustrations of polyethylene glycol (PEG)-Rh1 and PEG-Rh2 conjugate syntheses. 
A

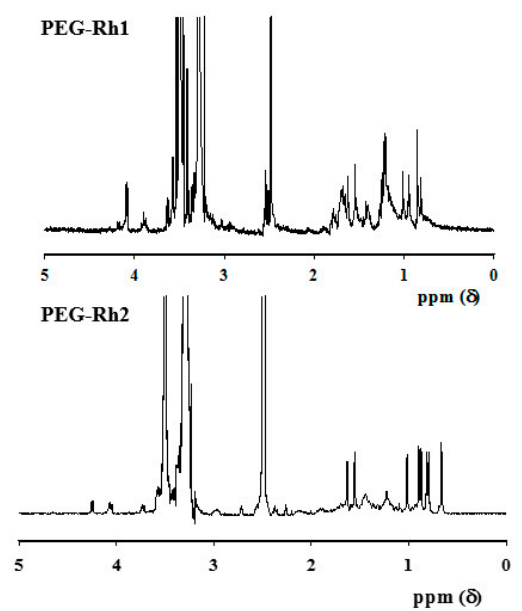

B

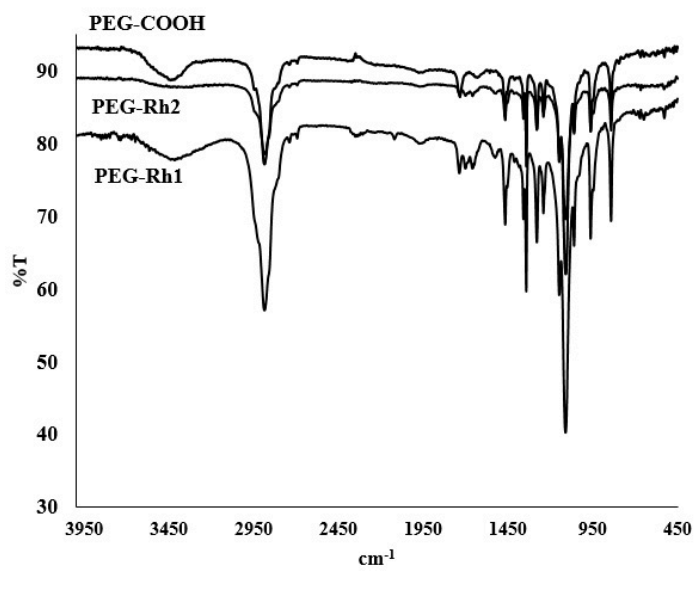

Figure 2. ${ }^{1} \mathrm{H}$ NMR (A) and FT-IR (B) spectra of the PEG-Rh1and PEG-Rh2 conjugates.

Though Rh2 is a PPD-type ginsenoside, a single conjugated PEG molecule is similar to PEG-PPD [17] but is less than PEG-CK, in which two molecules of PEG are conjugated [18]. The ester bond between PEG-COOH and the ginsenosides (Rh1 and Rh2) was confirmed with FT-IR spectroscopy (Figure 2B), which correlated with previous reports $[17,18]$. In vivo antitumor studies have reported that low-molecular-weight methoxy poly(ethylene glycol) methyl ether (mPEG 2000) (a conjugate of the anticancer drug gambogic acid with an ester bond) shows enhanced antitumor effects [14]. The results from a particle size analyzer confirmed that the particle sizes of synthesized PEG-Rh1 and PEG-Rh2 in terms of their average diameters in aqueous solution were $62 \pm 5.72 \mathrm{~nm}$ and $134 \pm 8.75$ nm, respectively (Figure 3A,B), which was smaller than the PEG-PPD conjugate (189 $\pm 15.69 \mathrm{~nm})$ [17]: further, the morphology of the conjugates was spherical, as could be seen after FE-TEM (Figure 3C,D).
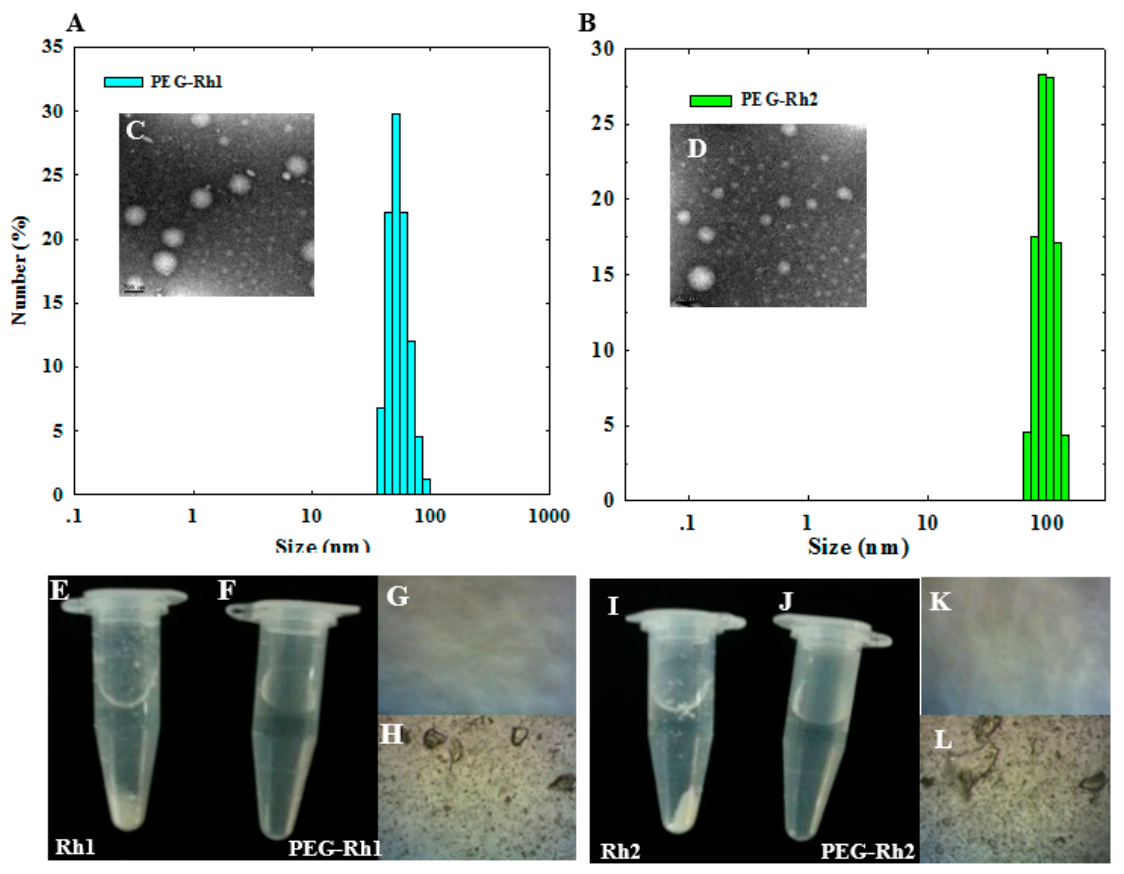

Figure 3. Particle size and spherical morphology of the PEG-Rh1 (A,C) and PEG-Rh2 (B,D) conjugates in aqueous solution. The scale bar in (C,D) represents $200 \mathrm{~nm}$. Non-soluble precipitates of free Rh1 (E,H) and Rh2 $(\mathbf{I}, \mathbf{L})$ compared to the increased solubility of the PEG-Rh1 $(\mathbf{F}, \mathbf{G})$ and PEG-Rh2 $(\mathbf{J}, \mathbf{K})$ conjugates. 


\subsection{Solubility of the PEG-Rh1 and PEG-Rh2 Conjugates}

PEG conjugation considerably enhances the solubility of several anticancer drugs, which further enhances their bioavailability and antitumor activities $[16,22,23]$. Due to the hydrophilic nature of PEG, it forms a hydrophilic outer layer by holding the hydrophobic ginsenosides Rh1 and Rh2, which form self-assembled micelles in aqueous medium. Thus, the prepared PEG-Rh1 and PEG-Rh2 conjugates were soluble in phosphate-buffered saline (PBS pH 7.4) or water at $2 \mathrm{mg}$ PEG-Rh1/mL (equivalent weight of $10.4 \mathrm{mg} / \mathrm{mL}$ Rh1) and $2 \mathrm{mg}$ PEG-Rh2/mL (equivalent weight of $8.7 \mathrm{mg} / \mathrm{mL}$ Rh1), whereas free Rh1 and Rh2 were insoluble at much lower concentrations (Figure 3). Increased solubility and anticancer activities in various hydrophobic anticancer drugs due to PEGylation have been reported [13,14,16,19,22,23].

\section{3. $p H$-Dependent Release of Rh1 and Rh2 from the PEG-Rh1 and PEG-Rh2 Conjugates}

Polymer conjugates are able to reach tumor because of the tumor's leaky vascular system (graphical abstract). Drugs are released into the tumor tissues through exposure to extra and intracellular stimuli. Specifically, $\mathrm{pH}$-responsive drug conjugates have gained attention due to the variations in $\mathrm{pH}$ between tumor tissues and normal tissues. Since the intracellular tumor cell $\mathrm{pH}(\mathrm{pH}$ 5.0-6.0) is lower than normal tissue $\mathrm{pH}$ conditions ( $\mathrm{pH} 7.4$ ), researchers have been able to develop $\mathrm{pH}$-responsive prodrug formulations to improve activities [16,30]. The hydrolysis of PEG-Rh1 and PEG-Rh2 was monitored by incubating samples under different $\mathrm{pH}$ conditions $(\mathrm{pH}$ 5.0, $\mathrm{pH}$ 7.4) over different time points. The amounts of hydrolyzed Rh1 and Rh2 were determined by HPLC (Figure 4).
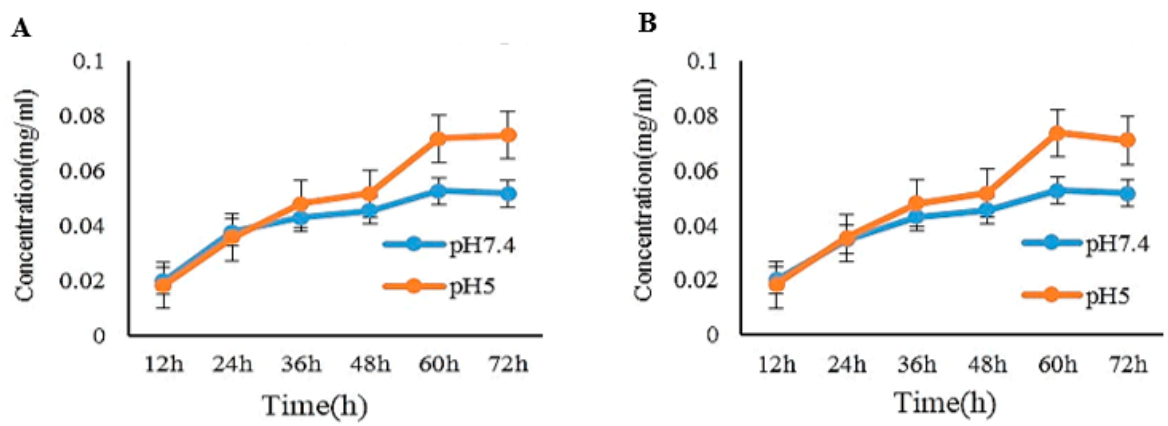

Figure 4. pH-dependent release of Rh1 and Rh2 from the PEG-Rh1 (A) and PEG-Rh2 (B) conjugates.

\subsection{In Vitro Cytotoxicity Inhibition of lipopolysaccharide (LPS)-Induced nitric oxide (NO) Production by PEG-Rh1 and PEG-Rh2 Conjugates}

Before evaluating the anti-inflammatory effects of PEG-COOH, ginsenoside Rh1, ginsenoside Rh2, PEG-Rh1, and PEG-Rh2, we examined their effects on the viability of RAW 264.7 cells. As is shown in Figure 5A,B, the viability of RAW 264.7 cells following treatment was not significantly decreased than control group. Since these ginsenosides showed no cytotoxicity effect on RAW 264.7 cells, we used up to $10 \mu \mathrm{M}$ Rh2 and PEG-Rh2 or $100 \mu \mathrm{M}$ Rh1 and PEG-Rh1 for the rest of our studies. As it has been previously reported that macrophage-like RAW 264.7 cells describe the actions of numerous anti-inflammatory mechanisms at the molecular stage [50], to further investigate whether PEG-Rh1 and PEG-Rh2 could function as inhibitors of nitric oxide (NO) production in this model, RAW 264.7 cells were stimulated with LPS $(1 \mu \mathrm{g} / \mathrm{mL})$ with or without cotreatment with ginsenoside Rh1, ginsenoside Rh2, PEG-Rh1, and PEG-Rh2. As is shown in Figure 6, ginsenoside Rh1, ginsenoside Rh2, PEG-Rh1, and PEG-Rh2 all dose-dependently repressed the NO production induced by LPS. Fascinatingly, it was observed that $10 \mu \mathrm{M}$ PEG-Rh2 inhibited LPS-induced NO production in RAW 264.7 cells at a greater level compared to the $100 \mu \mathrm{M}$ PEG-Rh1. 

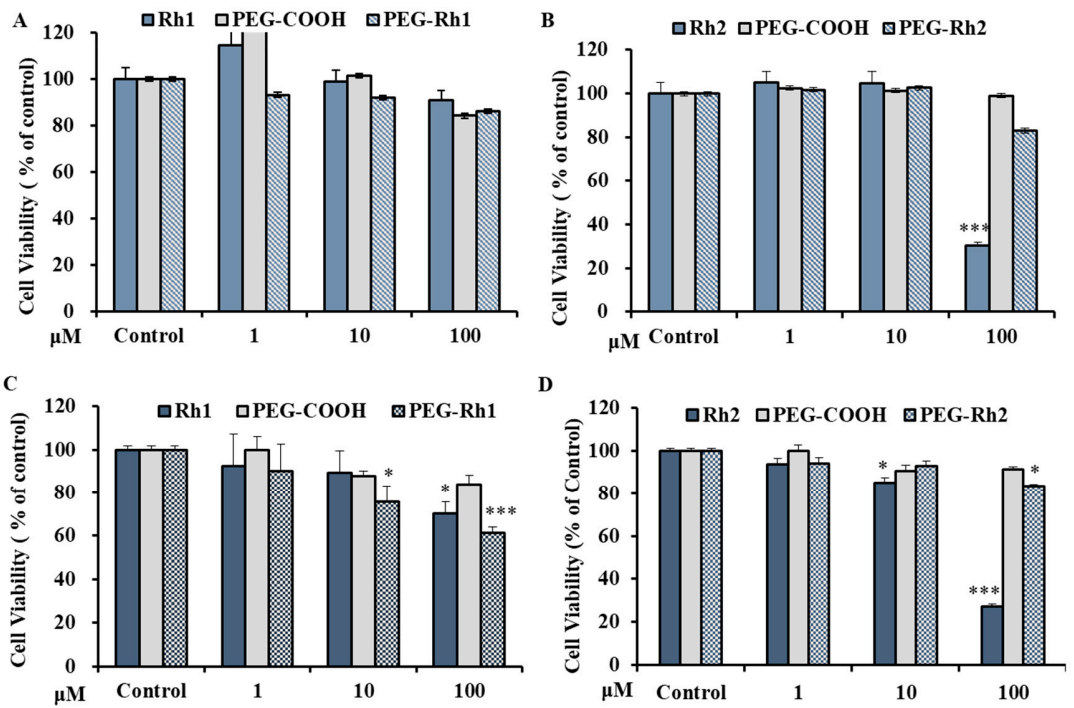

Figure 5. Cell cytotoxicity of PEG-Rh1 and PEG-Rh2 conjugates in RAW 264.7 cells (A,B) and A549 lung cancer cells $(\mathbf{C}, \mathbf{D})$ compared to the controls. All results are representative of three independent experiments; ${ }^{*} p<0.1$ and ${ }^{* * *} p<0.001$ versus control group.

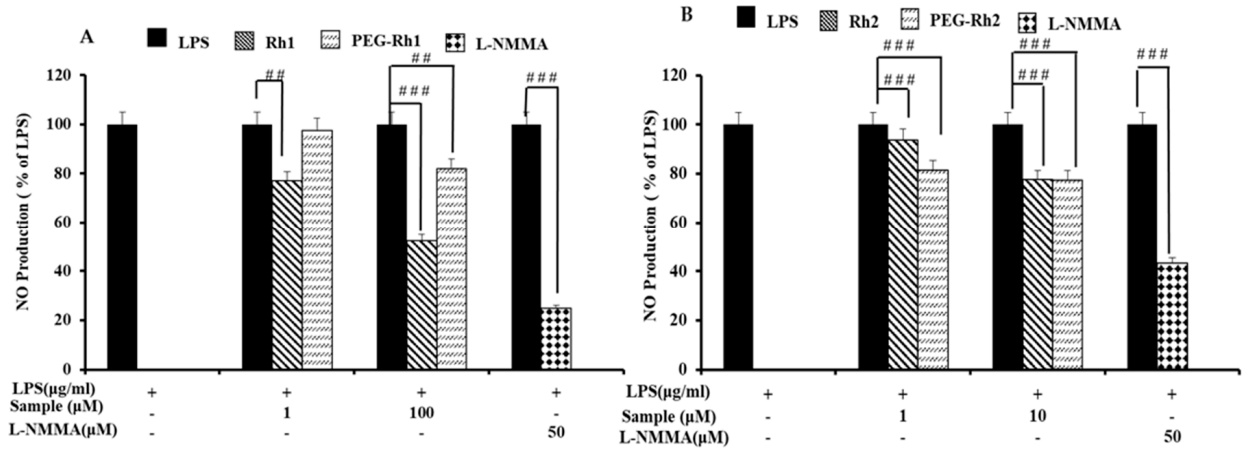

Figure 6. Effects of the PEG-Rh1 (A) and PEG-Rh2 (B) conjugates on nitric oxide production. LPS-treated RAW cells (to induce NO production and cause inflammation). LPS-lipopolysaccharide; NO-nitric oxide. ${ }^{\# \#} p<0.01,{ }^{\# \#} p<0.001$ as compared to the group treated with LPS alone.

\subsection{In Vitro Cytotoxicity of PEG-Rh1 and PEG-Rh2 in Lung Cancer A549 Cell Line}

First, we evaluated the toxicity profile of PEG-COOH in A549 cells. Our results showed that, following the treatment of cells at concentrations up to $100 \mu \mathrm{M}$ over a period of $48 \mathrm{~h}$, cell viability was not significantly reduced. The efficacy of PEG-Rh1 was compared to free ginsenoside Rh1 (Rh1) in A549 cells at different concentrations for $48 \mathrm{~h}$. We found that PEG-Rh1 exhibited high cytotoxicity compared to Rh1 at $100 \mu \mathrm{M}$ (Figure 5C). In addition, we found that in A549 cells, PEG-Rh2 was less toxic than Rh2 up to $100 \mu \mathrm{M}$ at $48 \mathrm{~h}$ (Figure 5D). Previously, it had been reported that PEGylated CK shows lower toxicity than its parent drug due to the slow release of drugs in pathophysiological $\mathrm{pH}$ condition $[17,18]$. However, the contributions of PEGylation to enhanced anticancer activities, bioavailability, solubility, and the targeted delivery of various anticancer drugs in vivo have been reported $[4,16,20,23]$. Thus, we suggest that the differences in responses between Rh1 and Rh2 after conjugation with PEG-COOH are related to differences in the glucose linkage at C-6 and C-3 in Rh1 and Rh2, respectively; the slow release of the compounds; and the high toxicity profile of free Rh2 in A549 cells. However, further experiments are needed to fully understand the differences between the molecular mechanism of PEG-Rh1 and PEG-Rh2. 


\section{Materials and Methods}

\subsection{Materials}

Polyethylene glycol monomethyl ether (mPEG, Mn 2000 g/mol), N,N'-dicyclohexyl carbodiimide (DCC), dimethyl amino pyridine (DMAP), triethylamine (TEA), anhydrous 1,4-dioxane, and succinic anhydride were purchased from Sigma Aldrich Co. (St. Louis, MO, USA). The ginsenosides Rh1 and Rh2 were purchased from the Lab of Hanbangbio, Kyung Hee University, Yongin, South Korea. All other chemicals were of analytical grade and were used as received.

\subsection{Synthesis of PEG-Rh1and PEG-Rh2Conjugates}

PEG-Rh1 and PEG-Rh2 were synthesized as reported in Ramya et al. [18] with a few modifications, as shown in Figure 1. First, $\alpha$-carboxy- $\omega$-methoxy polyethylene glycol (mPEG-COOH) was synthesized, followed by conjugation with Rh1 or Rh2. Carboxylated PEG was prepared using succinic anhydride as follows: mPEG (Mw $2000 \mathrm{da})(1 \mathrm{~g}, 0.5 \mathrm{mmol})$, succinic anhydride (0.06 g, $0.6 \mathrm{mmol})$, DMAP (0.061 g, $0.5 \mathrm{mmol})$, and TEA $(0.05 \mathrm{~g}, 0.5 \mathrm{mmol})$ were dissolved in anhydrous dioxane $(10 \mathrm{~mL})$ and stirred at room temperature for $24 \mathrm{~h}$. PE-COOH was then precipitated in diethyl ether and further filtered and dried under vacuum. Next, mPEG-COOH (0.044 g), DCC (0.06 g), and DMAP were added to the stirred solution. After $15 \mathrm{~min}$, Rh1 or Rh2 (dissolved in DMF) was added and stirred overnight, and the solution was further dialyzed (dialysis membrane (Mw cut-off: 3500)) against distilled water for $24 \mathrm{~h}$. Finally, the dialysate was filtered $(0.45-\mu \mathrm{M}$ filter syringe) and lyophilized to obtain the PEG-Rh1 and PEG-Rh2 conjugates.

\subsection{Characterizations of the Structure of the PEG-Rh1 and PEG-Rh2 Conjugates}

The PEG-Rh1 and PEG-Rh2 conjugates were characterized by ${ }^{1} \mathrm{H}$ NMR and FT-IR. For ${ }^{1} \mathrm{H}$ NMR, samples were dissolved in deuterated dimethylsulfoxide (DMSO- $\left.d_{6}\right)$, and the spectra were obtained at $300 \mathrm{MHz}$ (JEOL, Tokyo, Japan). FT-IR spectra of the PEG-Rh1 and PEG-Rh2 conjugates were obtained using a Perkin-Elmer FT-IR spectrophotometer with $\mathrm{KBr}$ pellets. FE-TEM was used to observe the morphology of conjugates (JEM-2000F, JEOL, Tokyo, Japan) at $200 \mathrm{kV}$. To prepare TEM samples, a drop of sample solution was placed onto a 200-mesh copper grid and air-dried, and a drop of phosphotungstic acid (PTA) solution was then added. This was used for negative staining. The stability and size of the conjugates were obtained by a particle analyzer, and the samples were dissolved in phosphate-buffered saline (PBS, pH 7.4).

\subsection{In Vitro $p H-D e p e n d e n t$ Release of Rh1 and Rh2 from the PEG-Rh1 and PEG-Rh2 Conjugates}

The PEG-Rh1 and PEG-Rh2 conjugates were dissolved in pH 7.4 (PBS) buffer, transferred to a cellulose dialysis membrane (Molecular weight cut-off (MWCO: 3500), and then placed in $30 \mathrm{~mL}$ of PBS ( $\mathrm{pH}$ 7.4) and acetate buffer ( $\mathrm{pH}$ 5.0). The samples were moderately shaken at $37{ }^{\circ} \mathrm{C}$ and $120 \mathrm{rpm}$. At different time intervals, 5-mL samples were withdrawn and replaced with fresh medium. To calculate the quantity of released Rh1 and Rh2, the withdrawn samples were extracted three times with water-saturated $n$-BuOH, evaporated, further dissolved in HPLC-grade $\mathrm{MeOH}$, and analyzed by HPLC (Agilent 1260, Palo Alto, CA, USA, $C_{18}$ column, $3.0 \times 50 \mathrm{~mm}$, particle size $2.7 \mu \mathrm{m}$ ) with acetonitrile (solvent $\mathrm{A}$ ) and distilled water (solvent $\mathrm{B}$ ). The flow rate was $0.6 \mathrm{~mL}$ per min, and the detection wavelength was $203 \mathrm{~nm}$.

\subsection{Cell Culture}

RAW 264.7 (murine macrophage obtained from the Korean Cell Bank (Seoul, South Korea)) cells were cultured at a density of $5 \times 10^{3}$ cells/well in a 96-well microplate in RPMI-1640 medium containing $10 \%(\mathrm{v} / \mathrm{v})$ fetal bovine serum (FBS) and $1 \%(\mathrm{v} / \mathrm{v})$ penicillin/streptomycin. 
The human non-small cell lung cancer cell line (A549) was obtained from the Korean Cell Bank (Seoul, South Korea). The cells were cultured in a $37^{\circ} \mathrm{C}$ humidified incubator in a $5 \% \mathrm{CO}_{2}$ atmosphere and maintained in RPMI-1640 culture media (GenDEPOT, Inc., Barker, TX, USA) supplemented with $10 \%$ fetal bovine serum (FBS), $100 \mathrm{IU} / \mathrm{mL}$ penicillin, and $100 \mu \mathrm{g} / \mathrm{mL}$ streptomycin (Gibco-BRL, Gaithersburg, MD, USA).

\subsection{Cell Viability Assay}

The cytotoxicity of PEG-COOH, ginsenoside Rh1, ginsenoside Rh2, PEG-Rh1, and PEG-Rh2 was analyzed with various concentrations of samples for $48 \mathrm{~h}$ by 3-(4,5-dimethylthiazol-2-yl)-2,5diphenyl-tertazolium bromide (MTT) assay. After the incubation period, $10 \mu \mathrm{L}$ of MTT solution $(5 \mathrm{mg} / \mathrm{mL})$ was added to each well. Plates were incubated for an additional $3-4 \mathrm{~h}$, and the formed formazan was dissolved in DMSO. The absorbance of each well was recorded on a Synergy 2 multimode microplate reader at $570 \mathrm{~nm}$ (BioteK, Winooski, VT, USA). Untreated cells were used as a control $(100 \%)$.

\subsection{Measurement of Nitrite Levels}

RAW 264.7 cells were pretreated with PEG-COOH, ginsenoside Rh1, ginsenoside Rh2, PEG-Rh1, or PEG-Rh2 for $1 \mathrm{~h}$ and then stimulated with $1 \mu \mathrm{g} / \mu \mathrm{L}$ lipopolysaccharide (LPS) in the presence of the samples and incubated for $48 \mathrm{~h}$. The nitrite level in the medium was calculated using Griess reagent: $100 \mu \mathrm{L}$ of supernatant was mixed with an equal volume of Griess reagent and measured at $540 \mathrm{~nm}$ by a microplate reader (Bio-Tek Instruments, Inc., Vinooski, VT, USA).

\section{Conclusions}

Korean ginseng is one of the most widely used remedies in Korea. It has unique triterpenoid saponins called ginsenosides, which are considered the active compounds responsible for the pharmacological effects of ginseng. The low solubility and tumor-targeted delivery of ginsenosides, which is due to avoiding off-target cytotoxicity, have been big challenges for clinical trials. To overcome these issues, water-soluble polymers with good biocompatible and biodegradable properties were loaded or conjugated with ginsenosides. Here, we described PEG conjugation applied to the ginsenosides Rh1 and Rh2 to increase solubility and cytotoxicity for tumor cells and inflammation. Finally, the anti-inflammation properties of PEG-Rh1 and PEG-Rh2 were evaluated through the inhibition of nitric oxide (NO) production.The higher drug conjugation efficiency, more solubility, smaller particle size with increased cytotoxicity to lung cancer of the PEG-Rh1 indicated that it exerts the overall efficacy of Rh1 for anticancer studies. However, reduced cytotoxicity of PEG-Rh2 than Rh2 with inhibition of NO production, the PEG-Rh2could be a potential drug candidate for inflammation related further studies.

Author Contributions: Conceptualization, R.M. and S.S.; methodology, V.C.-A., S.A., S.S., S.Y.S., Z.E.J.-P.; software, S.S.; resources, D.C.Y.; writing—original draft preparation, C.W. and R.M.; writing—review and editing, R.M.; supervision, D.C.Y. and S.-K.J.; project administration, D.C.Y.; funding acquisition, D.C.Y. and Y.J.K.

Funding: This research was supported by a grant from the Korea Institute of Planning \& Evaluation for Technology in Food, Agriculture, Forestry, \& Fisheries (KIPET NO: 317007-3), Republic of Korea and Natural Science Foundation of Shandong Province (ZR2019BC112).

Conflicts of Interest: The authors declare no conflict of interest.

\section{References}

1. Bray, F.; Ferlay, J.; Soerjomataram, I.; Siegel, R.L.; Torre, L.A.; Jemal, A. Global cancer statistics 2018: GLOBOCAN estimates of incidence and mortality worldwide for 36 cancers in 185 countries. Ca A Cancer J. Clin. 2018, 68, 394-424. [CrossRef] [PubMed]

2. Schirrmacher, V. From chemotherapy to biological therapy: A review of novel concepts to reduce the side effects of systemic cancer treatment (Review). Int. J. Oncol. 2019, 54, 407-419. [PubMed] 
3. Bonomi, P. Paclitaxel poliglumex (PPX, CT-2103): Macromolecular medicine for advanced non-small-cell lung cancer. Expert Rev. Anticancer Ther. 2007, 7, 415-422. [CrossRef] [PubMed]

4. Oostendorp, R.L.; Buckle, T.; Lambert, G.; Garrigue, J.S.; Beijnen, J.H.; Schellens, J.H.M.; van Tellingen, O. Paclitaxel in self-micro emulsifying formulations: Oral bioavailability study in mice. Investig. New Drugs 2010, 29, 768-776. [CrossRef] [PubMed]

5. Thambi, T.; Deepagan, V.G.; Yoon, H.Y.; Han, H.S.; Kim, S.-H.; Son, S.; Jo, D.-G.; Ahn, C.-H.; Suh, Y.D.; Kim, K.; et al. Hypoxia-responsive polymeric nanoparticles for tumor-targeted drug delivery. Biomaterials 2014, 35, 1735-1743. [CrossRef]

6. Thambi, T.; Park, J.H. Recent Advances in Shell-Sheddable Nanoparticles for Cancer Therapy. J. Biomed. Nanotechnol. 2014, 10, 1841-1862. [CrossRef]

7. Sivasubramanian, M.; Thambi, T.; Deepagan, V.G.; Saravanakumar, G.; Ko, H.; Kang, Y.M.; Park, J.H. Carboxymethyl Dextran-Cyclodextrin Conjugate as the Carrier of Doxorubicin. J. Nanosci. Nanotechnol. 2013, 13, 7271-7278. [CrossRef]

8. Sivasubramanian, M.; Thambi, T.; Park, J.H. Mineralized cyclodextrin nanoparticles for sustained protein delivery. Carbohydr. Polym. 2013, 97, 643-649. [CrossRef]

9. Min, K.H.; Park, K.; Kim, Y.-S.; Bae, S.M.; Lee, S.; Jo, H.G.; Park, R.-W.; Kim, I.-S.; Jeong, S.Y.; Kim, K.; et al. Hydrophobically modified glycol chitosan nanoparticles-encapsulated camptothecin enhance the drug stability and tumor targeting in cancer therapy. J. Control. Release 2008, 127, 208-218. [CrossRef]

10. Thambi, T.; You, D.G.; Han, H.S.; Deepagan, V.G.; Jeon, S.M.; Suh, Y.D.; Choi, K.Y.; Kim, K.; Kwon, I.C.; Yi, G.-R.; et al. Bioreducible Carboxymethyl Dextran Nanoparticles for Tumor-Targeted Drug Delivery. Adv. Healthc. Mater. 2014, 3, 1829-1838. [CrossRef]

11. Thambi, T.; Yoon, H.Y.; Kim, K.; Kwon, I.C.; Yoo, C.K.; Park, J.H. Bioreducible Block Copolymers Based on Poly(Ethylene Glycol) and Poly( $\gamma$-Benzyl l-Glutamate) for Intracellular Delivery of Camptothecin. Bioconjug. Chem. 2011, 22, 1924-1931. [CrossRef] [PubMed]

12. Thambi, T.; Son, S.; Lee, D.S.; Park, J.H. Poly(ethylene glycol)-b-poly(lysine) copolymer bearing nitroaromatics for hypoxia-sensitive drug delivery. Acta Biomater. 2016, 29, 261-270. [CrossRef] [PubMed]

13. Li, W.; Zhan, P.; de Clercq, E.; Lou, H.; Liu, X. Current drug research on PEGylation with small molecular agents. Prog. Polym. Sci. 2013, 38, 421-444. [CrossRef]

14. Cai, L.; Qiu, N.; Xiang, M.; Tong, R.; Yan, J.; He, L.; Shi, J.; Chen, T.; Wen, J.; Wang, W.; et al. Improving aqueous solubility and antitumor effects by nanosized gambogic acid-mPEG 2000 micelles. Int. J. Nanomed. 2014, 9, 243-255.

15. Liu, M.; Wang, L.; Hu, K.; Feng, J. Study on the stability of ginsenoside Rg1 before and after PEG modification. Med. Plant 2013, 4, 28-31.

16. Li, J.; Wang, Y.; Yang, C.; Wang, P.; Oelschlager, D.K.; Zheng, Y.; Tian, D.-A.; Grizzle, W.E.; Buchsbaum, D.J.; Wan, M. Polyethylene Glycosylated Curcumin Conjugate Inhibits Pancreatic Cancer Cell Growth through Inactivation of Jab1. Mol. Pharmacol. 2009, 76, 81-90. [CrossRef]

17. Mathiyalagan, R.; Kim, Y.J.; Wang, C.; Jin, Y.; Subramaniyam, S.; Singh, P.; Wang, D.; Yang, D.C. Protopanaxadiol aglycone ginsenoside-polyethylene glycol conjugates: Synthesis, physicochemical characterizations, and in vitro studies. Artif. Cellsnanomed. Biotechnol. 2016, 44, 1803-1809. [CrossRef]

18. Mathiyalagan, R.; Subramaniyam, S.; Kim, Y.J.; Natarajan, S.; Min, J.W.; Kim, S.Y.; Yang, D.C. Synthesis and pharmacokinetic characterization of a $\mathrm{pH}$-sensitive polyethylene glycol ginsenoside CK (PEG-CK) conjugate, Bioscience. Biotechnol. Biochem. 2014, 78, 466-468. [CrossRef]

19. Zhang, J.; Fan, X.; Liu, Y.; Bo, L.; Liu, X. Synthesis of poly(ethylene glycol)-metaxalone conjugates and study of its controlled release in vitro. Int. J. Pharm. 2007, 332, 125-131. [CrossRef]

20. Toshiyama, R.; Konno, M.; Eguchi, H.; Takemoto, H.; Noda, T.; Asai, A.; Koseki, J.; Haraguchi, N.; Ueda, Y.; Matsushita, K.; et al. Poly(ethylene glycol)-poly(lysine) block copolymer-ubenimex conjugate targets aminopeptidase $\mathrm{N}$ and exerts an antitumor effect in hepatocellular carcinoma stem cells. Oncogene 2019, 38, 244-260. [CrossRef]

21. Kang, J.-W.; Cho, H.-J.; Lee, H.J.; Jin, H.-E.; Maeng, H.-J. Polyethylene glycol-decorated doxorubicin/carboxymethyl chitosan/gold nanocomplex for reducing drug efflux in cancer cells and extending circulation in blood stream. Int. J. Biol. Macromol. 2019, 125, 61-71. [CrossRef] [PubMed]

22. Nayak, A.; Jain, A. In Vitro and In Vivo Study of Poly(ethylene glycol) Conjugated Ibuprofen to Extend the Duration of Action. Sci. Pharm. 2011, 79, 359-373. [CrossRef] [PubMed] 
23. Scott, L.C.; Yao, J.C.; Benson, A.B.; Thomas, A.L.; Falk, S.; Mena, R.R.; Picus, J.; Wright, J.; Mulcahy, M.F.; Ajani, J.A.; et al. A phase II study of pegylated-camptothecin (pegamotecan) in the treatment of locally advanced and metastatic gastric and gastro-oesophageal junction adenocarcinoma. Cancer Chemother. Pharmacol. 2009, 63, 363-370. [CrossRef] [PubMed]

24. Mohanan, P.; Subramaniyam, S.; Mathiyalagan, R.; Yang, D.-C. Molecular signaling of ginsenosides Rb1, $\operatorname{Rg} 1$, and Rg3 and their mode of actions. J. Ginseng Res. 2018, 42, 123-132. [CrossRef] [PubMed]

25. Boopathi, V.; Subramaniyam, S.; Mathiyalagan, R.; Yang, D.-C. Till 2018: A survey of biomolecular sequences in genus Panax. J. Ginseng Res. 2019. [CrossRef]

26. Wang, D.-D.; Kim, Y.-J.; Baek, N.I.; Mathiyalagan, R.; Wang, C.; Jin, Y.; Xu, X.Y.; Yang, D.-C. Glycosyltransformation of ginsenoside Rh2 to two novel ginsenosides by recombinant glycosyltransferase from Lactobacillus rhamnosus and its in vitro applications. J. Ginseng Res. 2019. [CrossRef]

27. Yang, J.-L.; Hu, Z.-F.; Zhang, T.-T.; Gu, A.-D.; Gong, T.; Zhu, P. Progress on the Studies of the Key Enzymes of Ginsenoside Biosynthesis. Molecules 2018, 23, 589. [CrossRef]

28. Yang, W.-Z.; Hu, Y.; Wu, W.-Y.; Ye, M.; Guo, D.-A. Saponins in the genus Panax L. (Araliaceae): A systematic review of their chemical diversity. Phytochemistry 2014, 106, 7-24. [CrossRef]

29. Tawab, M.A.; Bahr, U.; Karas, M.; Wurglics, M.; Schubert-Zsilavecz, M. Degradation of ginsenosides in humans after oral administration. Drug Metab. Dispos. 2003, 31, 1065. [CrossRef]

30. Mathiyalagan, R.; Subramaniyam, S.; Kim, Y.J.; Kim, Y.-C.; Yang, D.C. Ginsenoside compound K-bearing glycol chitosan conjugates: Synthesis, physicochemical characterization, and in vitro biological studies. Carbohydr. Polym. 2014, 112, 359-366. [CrossRef]

31. Markus, J.; Mathiyalagan, R.; Kim, Y.J.; Han, Y.; Perez, Z.E.J.; Veronika, S.; Yang, D.-C. Synthesis of Hyaluronic Acid and O-Carboxymethyl Chitosan-Stabilized ZnO-Ginsenoside Rh2 Nanocomposites Incorporated with Aqueous Leaf Extract of Dendropanax morbifera Léveille: In Vitro Studies as Potential Sunscreen Agents. New J. Chem. 2019, 43, 9188-9200. [CrossRef]

32. Moon, S.; Lee, H.; Mathiyalagan, R.; Kim, Y.; Yang, D.; Lee, D.; Min, J.; Jimenez, Z.; Yang, D. Synthesis of a Novel $\alpha$-Glucosyl Ginsenoside F1 by Cyclodextrin Glucanotransferase and Its In Vitro Cosmetic Applications. Biomolecules 2018, 8, 142. [CrossRef] [PubMed]

33. Mathiyalagan, R.; Yang, D.C. Ginseng nanoparticles: A budding tool for cancer treatment. Nanomedicine 2017, 12, 1091-1094. [CrossRef] [PubMed]

34. Yang, F.; Zhou, J.; Hu, X.; Yu, S.K.; Liu, C.; Pan, R.; Chang, Q.; Liu, X.; Liao, Y. Preparation and evaluation of self-microemulsions for improved bioavailability of ginsenoside-Rh1 and Rh2. Drug Deliv. Transl. Res. 2017, 7, 731-737. [CrossRef]

35. Han, M.; Hou, J.-G.; Dong, C.-M.; Li, W.; Yu, H.-L.; Zheng, Y.-N.; Chen, L. Isolation, synthesis and structures of ginsenoside derivatives and their anti-tumor bioactivity. Molecules 2010, 15, 399-406. [CrossRef]

36. Gai, Y.; Ma, Z.; Yu, X.; Qu, S.; Sui, D. Effect of ginsenoside Rh1 on myocardial injury and heart function in isoproterenol-induced cardiotoxicity in rats. Toxicol. Mech. Methods 2012, 22, 584-591. [CrossRef]

37. Jeong, J.-J.; Kim, B.; Kim, D.-H. Ginsenoside Rh1 Eliminates the Cytoprotective Phenotype of Human Immunodeficiency Virus Type 1-Transduced Human Macrophages by Inhibiting the Phosphorylation of Pyruvate Dehydrogenase Lipoamide Kinase Isozyme 1. Biol. Pharm. Bull. 2013, 36, 1088-1094. [CrossRef]

38. Jung, J.-S.; Shin, J.A.; Park, E.-M.; Lee, J.-E.; Kang, Y.-S.; Min, S.-W.; Kim, D.-H.; Hyun, J.-W.; Shin, C.-Y.; Kim, H.-S. Anti-inflammatory mechanism of ginsenoside Rh1 in lipopolysaccharide-stimulated microglia: Critical role of the protein kinase a pathway and hemeoxygenase-1 expression. J. Neurochem. 2010, 115, 1668-1680. [CrossRef]

39. Park, E.K.; Choo, M.K.; Han, M.J.; Kim, D.H. Ginsenoside Rh1 Possesses Antiallergic and Anti-Inflammatory Activities. Int. Arch. Allergy Immunol. 2004, 133, 113-120. [CrossRef]

40. Choi, Y.-J.; Yoon, J.-H.; Cha, S.-W.; Lee, S.-G. Ginsenoside Rh1 inhibits the invasion and migration of THP-1 acute monocytic leukemia cells via inactivation of the MAPK signaling pathway. Fitoterapia 2011, 82, 911-919. [CrossRef]

41. Lee, Y.; Jin, Y.; Lim, W.; Ji, S.; Choi, S.; Jang, S.; Lee, S. A ginsenoside-Rh1, a component of ginseng saponin, activates estrogen receptor in human breast carcinoma MCF-7 cells. J. Steroid Biochem. Mol. Biol. 2003, 84, 463-468. [CrossRef] 
42. Tam, D.N.H.; Truong, D.H.; Nguyen, T.T.H.; Quynh, L.N.; Tran, L.; Nguyen, H.D.; Shamandy, B.e.; Le, T.M.H.; Tran, D.K.; Sayed, D.; et al. Ginsenoside Rh1: A Systematic Review of Its Pharmacological Properties. Planta. Med. 2018, 84, 139-152. [CrossRef] [PubMed]

43. Cheng, C.-C.; Yang, S.-M.; Huang, C.-Y.; Chen, J.-C.; Chang, W.-M.; Hsu, S.-L. Molecular mechanisms of ginsenoside Rh2-mediated G1 growth arrest and apoptosis in human lung adenocarcinoma A549 cells. Cancer Chemother. Pharmacol. 2005, 55, 531-540. [CrossRef] [PubMed]

44. Musende, A.G.; Eberding, A.; Wood, C.; Adomat, H.; Fazli, L.; Hurtado-Coll, A.; Jia, W.; Bally, M.B.; Guns, E.T. Pre-clinical evaluation of Rh2 in PC-3 human xenograft model for prostate cancer in vivo: Formulation, pharmacokinetics, biodistribution and efficacy. Cancer Chemother. Pharmacol. 2009, 64, 1085-1095. [CrossRef] [PubMed]

45. Hou, J.; Xue, J.; Lee, M.; Liu, L.; Zhang, D.; Sun, M.; Zheng, Y.; Sung, C. Ginsenoside Rh2 improves learning and memory in mice. J. Med. Food 2013, 16, 772-776. [CrossRef] [PubMed]

46. Oh, S.-J.; Lee, S.; Choi, W.-Y.; Lim, C.-J. Skin anti-photoaging properties of ginsenoside Rh2 epimers in UV-B-irradiated human keratinocyte cells. J. Biosci. 2014, 39, 673-682. [CrossRef]

47. Hwang, J.-T.; Kim, S.-H.; Lee, M.-S.; Kim, S.H.; Yang, H.-J.; Kim, M.-J.; Kim, H.-S.; Ha, J.; Kim, M.S.; Kwon, D.Y. Anti-obesity effects of ginsenoside Rh2 are associated with the activation of AMPK signaling pathway in 3T3-L1 adipocyte. Biochem. Biophys. Res. Commun. 2007, 364, 1002-1008. [CrossRef]

48. Park, E.K.; Lee, E.J.; Lee, S.H.; Koo, K.H.; Sung, J.Y.; Hwang, E.H.; Park, J.H.; Kim, C.W.; Jeong, K.C.; Park, B.K.; et al. Induction of apoptosis by the ginsenoside Rh2 by internalization of lipid rafts and caveolae and inactivation of Akt. Br. J. Pharm. 2010, 160, 1212-1223. [CrossRef]

49. Park, H.-M.; Kim, S.-J.; Kim, J.-S.; Kang, H.-S. Reactive oxygen species mediated ginsenoside Rg3- and Rh2-induced apoptosis in hepatoma cells through mitochondrial signaling pathways. Food Chem. Toxicol. 2012, 50, 2736-2741. [CrossRef]

50. Ahn, S.; Siddiqi, M.H.; Noh, H.-Y.; Kim, Y.-J.; Kim, Y.-J.; Jin, C.-G.; Yang, D.-C. Anti-inflammatory activity of ginsenosides in LPS-stimulated RAW 264.7 cells. Sci. Bull. 2015, 60, 773-784. [CrossRef]

Sample Availability: Not available.

(C) 2019 by the authors. Licensee MDPI, Basel, Switzerland. This article is an open access article distributed under the terms and conditions of the Creative Commons Attribution (CC BY) license (http://creativecommons.org/licenses/by/4.0/). 